\title{
Reasons for non-attendance nutrition appointment among medically underserved community in Rural Mississippi
}

\author{
Amir Alakaam*1, Jennifer Lemacks², Ashley Parker² \\ ${ }^{1}$ Department of Nutrition and Dietetics, University of North Dakota, Grand Forks, North Dakota, United States \\ ${ }^{2}$ Department of Nutrition and Food Systems, The University of Southern Mississippi, Hattiesburg, Mississippi, United States
}

\author{
Received: May 31, 2018 \\ Accepted: July 1, 2018 \\ Online Published: July 6, 2018 \\ DOI: $10.5430 /$ jer.v4n2p35 \\ URL: https://doi.org/10.5430/jer.v4n2p35
}

\begin{abstract}
Objective: This study sought to examine the reasons for nonattendance of nutrition appointments and explore the determinants that contribute to this phenomenon among medically underserved and uninsured individuals.

Methods: A cross-sectional quantitative study was conducted with five sections questionnaires distributed at a healthcare clinic in a rural area in south Mississippi. Participants $(n=346)$ were surveyed who had attended the clinic for a health appointment. Nutrition appointment attendance, reasons to miss a scheduled nutrition appointment, and effective appointment reminders were evaluated. Descriptive statistics were determined for the variables, Chi square and bivariate correlation tests were used to determine relationships between participants' demographics, health conditions, and other variables.

Results: About $87 \%$ of participants indicated that they had not attended a nutrition appointment and $26.8 \%$ indicated that they had missed a nutrition appointment. Most participants specified that forgetfulness (39\%) and transportation problems (25\%) were the most likely reasons to miss a nutrition appointment. Most indicated that a phone call would be the most effective appointment reminder. About half of participants believed the reason behind missing a nutrition appointment is that their physicians did not place importance on attending such appointment. No significant association or differences were found between the variables. Conclusion: Findings can be used to improve access to nutrition counseling among underserved patients, and to develop effective appointment reminders to decrease nonattendance rates. Future research is warranted to analyze the effect that nutrition appointments has on individual's health.
\end{abstract}

Key Words: Health service, Nutrition care access, Nutrition counseling, Rural health

\section{INTRODUCTION}

Nutrition therapy is an individualized process used to motivate patients to create genuine and enduring change towards a healthy diet in order to reduce chronic disease risk. ${ }^{[1]}$ Registered and Licensed Dietitians are a health care professional that administers this process, considered nutrition experts and have knowledge and experience pertaining to individuals' nutritional health. ${ }^{[1]}$ Patients who regularly fail to attend nutrition appointments significantly increase their risk for disease complications. ${ }^{[2]}$ Attending regularly scheduled nutrition appointments is associated with progressive management of many chronic diseases such as diabetes mellitus and

\footnotetext{
*Correspondence: Amir Alakaam; Email: amir.alakaam@UND.edu; Address: Department of Nutrition \& Dietetics, University of North Dakota, 400 Oxford Street Stop 8237, Grand Forks, ND, 58202, United States.
} 
hypertension; conversely, nonattendance of nutrition appointments associated with adverse health outcomes and increased risk of chronic diseases due to poor nutrition management. ${ }^{[3]}$

Average nonattendance rates vary from $3 \%$ to $80 \%$, with self-reported nonattendance in primary care settings being greater than $50 \%$. ${ }^{[4-6]}$ These high rates of nonattendance are associated with prolonged treatment of critical illnesses, causing a strain on health service resources and the financial stability of health clinics. ${ }^{[7-9]}$ Furthermore, a reported average no-show rate of 62 appointments per day has resulted in an estimated annual cost of $\$ 3,000,000$ across healthcare systems. ${ }^{[9,10]}$

There are many factors that have been identified to have an influence on nonattendance for healthcare appointments including limited transportation, lack of medical insurance, forgetfulness, undesirable experience with past appointments, negative attitude toward nutrition counseling, and lack of social support. ${ }^{[11,12]}$ Studies mentioned specifically that forgetfulness and lack of transportation have been shown to be the main reasons for nonattendance of nutrition appointments in several healthcare settings. ${ }^{[12-16]}$

Researchers had implemented measures to reduce nonattendance rates in healthcare facilities while recovering revenue. ${ }^{[17]}$ Cell phone message has shown significant reduction of missed appointments from $11.4 \%$ to $7.8 \% .^{[18]}$ Other intervention procedures explored the use of three different interventions: multiple phone calls and texting, patient education on the importance of attending clinic appointments, and the systematic updating of patient contact information each visit. ${ }^{[19]}$ It was determined that the combination of more than one intervention was most effective in reducing nonattendance rate. ${ }^{[19]}$

In 2013, we conducted several research projects intended to improve obesity and chronic disease management and examine community-based solution for health disparities in rural areas of Mississippi. ${ }^{[20,21]}$ The projects also designed a strategy to improve underserved patients' engagement with health care providers such as primary care physicians and registered dietitians. ${ }^{[20,21]}$ The present study is part of this project. Given the high number of people who do not attend nutrition appointments in health facilities, there is a need for strategies to evaluate the various determinants that impact the decision for people to attend nutrition appointments. Furthermore, limited research has been conducted to understand the causes and consequences of nonattendance of nutrition appointments in rural and underserved communities. The goals of this study were to (a) examine the reasons for nonattendance of nutrition appointments; (b) explore the determinants that contribute to this phenomenon; and (c) determine an effective method of appointment reminder among an underserved population in an outpatient primary care setting.

\section{Methods}

\subsection{Design}

This study was conducted at a primary health care center in south Mississippi. The center is in a rural area and accessible to low-income individuals, primarily, the underserved and underinsured population. Individuals were invited to participate in the study at the health center's waiting area, soon after they checked in. Participants were asked to complete a questionnaire using a tablet device which took 10-15 minutes to complete. All participant responses were saved electronically in a password-protected folder and the data were not identifiable. The University of Southern Mississippi Institutional Review Board approved the study protocol.

\subsection{Sample}

The target population included community health clinic patients who were referred to nutrition counseling either by physicians, or were patients who had an appointment for nutrition counseling. Patients were considered eligible if they met the following self-reported criteria: age above 18 years, ability to speak and read English, attend the clinic for a health-related appointment, and treated at the clinic for common nutrition-related conditions (diabetes, hypertension, obesity, cardiovascular disease, or dyslipidemia). Patients who did not meet these criteria were deemed ineligible for the study.

\subsection{Measures}

The study measures included 25 questions divided into 5 sections, beginning with 3 inclusion criteria questions addressing age and clarifying whether individuals were patients at the clinic and diagnosed with nutrition-related conditions. Additional questions requested that participants provide socio-demographic information regarding age, gender, race, marital status, education level, income level, health insurance status and (when applicable) health insurance provider.

Participants who answered "yes" to either being referred to a nutrition appointment or having attended a nutrition appointment in the past were asked 7 questions about their opinion and experience with the nutrition counseling process, registration and check-in procedure, and appointment scheduling method. Participants also asked to respond to questions answered by Likert scale, regarding potential reasons for missing a nutrition appointment, reminder procedures to reduce nonattendance, and method they believed is most effective 
as an appointment reminder. Participants were also asked about the most likely reasons to not call to cancel a nutrition appointment beforehand if they were to or ever have missed a nutrition appointment. The study instrument was adapted from a validated previous instrument. ${ }^{[12,19,22]}$

\subsection{Analysis}

The researcher used the Statistical Package for Social Sciences software (IBM SPSS for Windows, version 22.0, 201, Chicago, IL) for data analysis. Descriptive statistics, including frequencies and percentages were determined for all variables. Chi square and bivariate correlation tests were used to examine associations between demographics variables (age, income, sex, and race) and reasons for missing an appointment, reasons to not call and cancel nutrition appointments, and the most effective appointment reminder. Significance was considered at $\alpha<0.05$.

\section{Results}

\subsection{Participants' characteristics and nutrition-related disease}

Data was collected from 435 individuals who attended a rural primary health clinic in south Mississippi. Three participants were excluded due to age, 26 for not attending the clinic for a health problem, and 60 for not reporting a nutrition-related health condition. Three hundred and forty-six participants met inclusion criteria and were eligible for further analysis $(\mathrm{N}=346)$.

Most participants were female and African American, the mean age was 54.8 (SD 11.8) years with approximately two thirds between 45 and 64 years of age. Most participants reported attaining at least a high school diploma or equivalent, and a yearly household income less than $\$ 19,000$ per year and unemployed. With regards to medical history, most participants indicated that they had hypertension and other chronic diseases. Table 1 provides a complete list of the participants' characteristics.

\subsection{Nutrition appointment referral and attendance}

There were unique participants who had either been referred for a nutrition appointment at the clinic $(n=44,13.3 \%$ of total sample) or had indicated they had attended a nutrition appointment in the past $(n=42,12.9 \%)$. Of the 44 who had been referred at the clinic, the majority were referred by a physician $(76.7 \%)$ followed by a registered nurse or other healthcare provider $(23.3 \%)$. Of the participants $(n=60)$ who had either been referred to a nutrition appointment at the clinic or had attended a nutrition appointment in the past, 11 $(18.3 \%)$ indicated that they had previously missed a nutrition appointment. Those who had attended a nutrition appoint- ment in the past $(n=42)$ strongly agreed with the following: (1) nutritionist/dietitian understood my needs $(78.6 \%, \mathrm{n}=$ 33); (2) nutritionist/dietitian explained things well to help me understand my condition $(88.1 \%, \mathrm{n}=37)$; and (3) after attending the appointment, I have a clear plan $(71.4 \%, \mathrm{n}=$ $30)$ and I feel confident to make health changes $(80.5 \%, \mathrm{n}=$ 33).

Table 1. Characteristics of the sample $(\mathrm{N}=346)$

\begin{tabular}{|c|c|}
\hline Characteristic & n (\%) \\
\hline \multicolumn{2}{|l|}{ Gender } \\
\hline Female & $220(65.3)$ \\
\hline Male & $114(33.8)$ \\
\hline \multicolumn{2}{|l|}{ Race } \\
\hline Black/African American & $226(67.1)$ \\
\hline White & $92(27.3)$ \\
\hline Mixed Races & $5(1.5)$ \\
\hline Hispanic/Latino & $4(1.2)$ \\
\hline American Indian & $3(0.9)$ \\
\hline Asian & $2(0.6)$ \\
\hline \multicolumn{2}{|l|}{ Education Level } \\
\hline High School & $154(45.7)$ \\
\hline Some College & 59 (17.5) \\
\hline Less than High School & 40 (11.9) \\
\hline 2-Year Vocational & $34(10.1)$ \\
\hline 4-Year college degree & $34(10.1)$ \\
\hline Graduate or advanced & $11(3.3)$ \\
\hline \multicolumn{2}{|l|}{ Household Income } \\
\hline$\$ 29,999$ or less & $186(55.2)$ \\
\hline$\$ 30,000-\$ 49,999$ & $22(6.5)$ \\
\hline$\$ 50,000-69,999$ & $9(8.7)$ \\
\hline$\$ 70,000$ and above & $3(0.9)$ \\
\hline Unemployed & 109 (32.3) \\
\hline \multicolumn{2}{|l|}{ Marital Status } \\
\hline Single & $141(41.8)$ \\
\hline Married or cohabitating & $117(34.7)$ \\
\hline Divorced or Separated & $71(21.1)$ \\
\hline \multicolumn{2}{|l|}{ Health Condition } \\
\hline Hypertension & $294(87.2)$ \\
\hline High Cholesterol & $141(42.5)$ \\
\hline Diabetes Mellitus & 121 (35.9) \\
\hline Obesity & $115(34.2)$ \\
\hline Heart Disease & $44(13.3)$ \\
\hline \multicolumn{2}{|l|}{ Health Insurance Coverage } \\
\hline Yes & $229(68.0)$ \\
\hline No & $100(29.7)$ \\
\hline
\end{tabular}

Note. Percentages in a category do not total $100 \%$ because some participants refused to answe certain questions; Percentages of "Health Condition" category total more than $100 \%$ because multiple answers were allowed. 
3.3 Reasons for missed or no show appointments and best reminder mode

Forgetfulness $(38 \%, \mathrm{n}=146)$ followed by transportation problems $(24 \%, \mathrm{n}=127)$ and unable to miss work $(22.3 \%$, $\mathrm{n}=91$ ) were the most likely reasons to miss a nutrition appointment across the sample (see Table 2). Most of the participants $(82.1 \%)$ believed that a phone call would be the most effective appointment reminder, followed by a text message on their cellphone (51.6\%) (see Table 3).

Table 2. Reported reasons for missing nutrition appointments $(\mathrm{N}=346)$

\begin{tabular}{llllll}
\hline Reason & $\begin{array}{l}\text { Most Likely } \\
\text { (\%) }\end{array}$ & $\begin{array}{l}\text { Very Likely } \\
\text { (\%) }\end{array}$ & $\begin{array}{l}\text { Sometimes } \\
\text { Likely (\%) }\end{array}$ & $\begin{array}{l}\text { Very Unlikely } \\
\text { (\%) }\end{array}$ & Not Likely (\%) \\
\hline Unable to miss work & 8.9 & 4.2 & 9.2 & 5.9 & 67.7 \\
Forgetfulness & 8.3 & 11.9 & 17.8 & 6.5 & 51.4 \\
Transport problems & 6.8 & 6.5 & 10.7 & 8.6 & 63.2 \\
Feeling better & 5.6 & 3.9 & 8.3 & 8.9 & 69.1 \\
Weather conditions & 5.0 & 4.5 & 10.4 & 7.7 & 68.0 \\
Lack of health insurance & 0.9 & 1.8 & 5.6 & 8.9 & 78.6 \\
Lack of instruction on & 0.9 & 1.8 & 5.6 & 8.9 & 78.6 \\
appointment scheduling process & & 1.5 & 2.4 & 6.5 & 84.9 \\
Lack of daycare & 0.6 & & & & \\
\hline
\end{tabular}

Table 3. Reported most effectiveness nutrition appointment reminders variable $(\mathrm{N}=346)$

\begin{tabular}{llllll}
\hline Reminder & $\begin{array}{l}\text { Most Effective } \\
\text { (\%) }\end{array}$ & $\begin{array}{l}\text { Very Effective } \\
\mathbf{( \% )}\end{array}$ & $\begin{array}{l}\text { Sometimes Effective } \\
\mathbf{( \% )}\end{array}$ & $\begin{array}{l}\text { Least Effective } \\
\text { (\%) }\end{array}$ & $\begin{array}{l}\text { Not Effective } \\
\text { (\%) }\end{array}$ \\
\hline Phone call & 75.4 & 9.2 & 3.9 & 2.4 & 0.9 \\
Text messages & 46.6 & 11.0 & 7.4 & 7.7 & 16.9 \\
Letter/Mail & 14.2 & 18.4 & 12.8 & 23.4 & 18.4 \\
Email & 12.8 & 9.2 & 10.4 & 23.2 & 30.7 \\
\hline
\end{tabular}

The most reported reason that participants selected if they were to or ever had missed a nutrition appointment without calling beforehand ("no show" appointment) was the physician did not place importance on attending a nutrition appointment (see Table 4).

Table 4. Reported reasons to not call and cancel nutrition appointments $(\mathrm{N}=346)$

\begin{tabular}{ll}
\hline Reason & $\mathbf{n ~ ( \% )}$ \\
\hline Doctor didn't place importance on attending appointment & $163(49.7)$ \\
Emergency & $117(33.8)$ \\
Forgot to call & $99(30.3)$ \\
Forgot about the appointment & $46(14)$ \\
Didn't think it was necessary & $44(13.4)$ \\
Lack of access to phone & $33(10.1)$ \\
Embarrassed & $7(2.1)$ \\
Phone anxiety & $5(1.5)$ \\
Do not value the dietitians/nutritionists' opinion & $4(1.2)$ \\
The counseling isn't helping & $3(0.9)$ \\
\hline
\end{tabular}

\subsection{Associations and group means testing}

Chi square tests were used to examine associations between sex, race (White versus non-White), and marital status (married versus not married) and reasons for missed appointments (forgetfulness, transport problems, lack of health insurance, lack of instruction on appointment scheduling process, unable to miss work, feeling better, lack of daycare, and weather conditions), reasons to not call and cancel nutrition appointments (embarrassed, emergency, forgot to call, lack of access to phone, didn't think it was necessary, the counseling isn't helping, forgot about the appointment, phone anxiety, doctor didn't place importance on attending appointment, and do not value the dietitian's/nutritionist's opinion), and the most effective appointment reminder (phone call, email, and letter/mail and text messages). A significant association was found between race and lack of phone access $\left(\chi^{2}(1)=8.13, p=.004\right)$ where $18 \%$ of whites reported it as a very-most likely reason to miss an appointment compared to $7.3 \%$ of nonwhites. Gender differences were also observed with $10.8 \%$ females versus $22.9 \%$ males reported very-most likely to miss an appointment due to lack of health insurance $\left(\chi^{2}(1)=10.88, p=.028\right)$, and $27 \%$ women versus $4.5 \%$ men selected very-most likely to miss an appointment due to weather conditions $\left(\chi^{2}(1)=9.79, p=.044\right)$. An association was also observed between gender and selecting embarrassed as a reason for not calling to cancel a nutrition appointment with $4.6 \%$ men versus $0.9 \%$ women $\left(\chi^{2}(1)=4.54, p=.033\right)$. 
Correlation tests examined the association between age and income levels and reasons for missed appointments, reasons to not call and cancel nutrition appointments and the most effective appointment reminder. Age was inversely associated with unable to miss work $(\mathrm{r}=-0.18, p=.001)$, feeling better $(\mathrm{r}=-0.15, p=.009)$, forgot about my appointment $(\mathrm{r}=-0.12$, $p=0.037$ ), and not valuing the dietitian's or nutritionist's opinion $(\mathrm{r}=-.12, p=.031)$ as reasons to miss a nutrition appointment. On the contrary, age was positively associated with my doctor did not place the importance on attending a nutrition appointment for my condition $(\mathrm{r}=.11, p=.031)$ and emergency $(\mathrm{r}=.13, p=.020)$ as reasons for missing an appointment.

Income levels were inversely associated with forgetfulness $(\mathrm{r}=-0.15, p=.006)$, transportation problems $(\mathrm{r}=-0.16, p=$ .006 ), and positively associated with unable to miss work ( $\mathrm{r}$ $=.24, p<.001)$ as reasons to most likely miss an appointment. With regards to most effective appointment reminders, income level was positively associated with selecting email $(\mathrm{r}=.39, p<.001)$, age was inversely associated with selecting email $(\mathrm{r}=-0.33, p<.001)$ and text $(\mathrm{r}=-0.25, p<.001)$ as a reminder method. No other significant correlational associations were noted.

\section{Discussion}

This study provides an overview of nonattendance of nutrition appointments among a low-income, underserved population in rural area of southern U.S. The result indicates that nonattendance rates among underserved and underinsured patients are high. Despite the fact that nutrition appointment attendance has been shown to be positively associated with the management of chronic diseases, ${ }^{[10,11]}$ the nutrition appointment nonattendance rate reported in this study is consistent with other studies who had reported average rates on nutrition appointment nonattendance. ${ }^{[4,5]}$ The majority of our participants reported having chronic diseases such as hypertension, obesity, and heart disease, and yet did not attend a nutrition appointment or had missed a scheduled appointment. Thus, there is a gap in the need for nutrition intervention in outpatient primary care clinics.

Approximately half of our participants believed the reason behind missing a nutrition appointment is that their physicians did not place importance on attending such appointment. Prior studies indicate that patient-physician relationships and communication is an important factor in nutrition appointment attendance. ${ }^{[23,24]}$ Physicians and other health professionals should express the importance of nutrition counseling to their patients, and should identify registered dietitians as a powerful partner in managing patient's condition. According to a survey of providers $(n=500)$ across the U.S. previously,

Published by Sciedu Press providers cited the dietitian or nutritionist as the most qualified health professional for obesity management, indicated a need for physician training in nutrition and exercise counseling to improve obesity care and suggested the inclusion of specific diet or physical activity tips in patient charts as needed practice-based changes. ${ }^{[25]}$ Therefore, registered dietitians may need to advocate for their services to reinforce or enhance the physician's message and provide support for obesity management in primary care.

Participants indicated that forgetfulness was the second most likely reason for them to miss a nutrition appointment. Previous studies ${ }^{[12,25]}$ had also showed that forgetfulness is one of the main factor that can influence patient's nonattendance at health facility, in addition to other factors such as transportation problems, lack of medical insurance, forgetfulness, lack of health education, and negative attitude toward nutrition counseling to be related to nutrition appointment nonattendance. ${ }^{[12,26]}$ This finding is important as it displays the importance of an organized and consistent appointment reminder systems at healthcare clinics.

The present finding also indicates that underserved and uninsured populations specifically, report transportation as a big problem to access healthcare. A study looking at HIVinfected women and transportation barriers showed that it is "very difficult" to access healthcare and attend scheduled appointments as necessary. ${ }^{[14]}$ This is also true of rural patients in comparison to their urban counterparts. ${ }^{[27,28]}$ Rural communities often lack adequate public transportation to allow underserved populations attend health appointments. This is a major issue in Mississippi with a largely rural population.

Another aim of this study was to assess the effectiveness of appointment reminders on nutrition appointment attendance. Most participants believed that a phone call would be the most effective form of appointment reminder, which was consistent with previous studies. ${ }^{[17,18]}$ It was also noted in our sample that younger age preferred text and email as reminder methods. Combining phone calls, text message, and patient education has been shown to be effective in reducing nonattendance. ${ }^{[19]}$ Thus, the utilization of mixed-methods for reminders may be integral to meet the needs of different age and income populations while combatting forgetfulness, which was the most commonly reported reason for nonattendance.

Most participants were at a low socioeconomic status and had a high school diploma or less. It has been observed that people with lower education levels had a tendency to skip scheduled appointments and were more likely to misunderstand the importance of scheduled appointments. ${ }^{[29]}$ Furthermore, patients who are unable to understand the im- 
portance of appointments or have inadequate knowledge of what these appointments consist of, are potentially demotivated to attend nutrition counselling services. ${ }^{[29-31]}$ This amplifies the importance of productive patient-provider conversations about the role of nutrition in disease management, especially among health disparate individuals who may be at risk for developing chronic disease.

This study had some limitations, the survey was selfadministered, potentially causing a lack of ability to clarify questions or to probe; however, research staff was present to clarify questions and concerns. The study instrument was adapted from other studies valid and reliable instruments, this may cause some limitation, as those instruments were administrated in different populations. Another possible limitation is that this study used purposive sampling method, the study sample may not represent the total underserved population who have been referred for nutrition counseling; however, our study selected the site based on the clinic's mission and history of serving underserved populations.

\section{Conclusion}

This study provides important information for nutrition management programs and outpatient clinics for retention of underserved populations in health care setting. Findings can be used by other researchers to further explore how nonattendance of nutrition appointments vary across different populations and locations, and to determine the health impact that nonattendance of nutrition appointments have on individual health. There is still a need for further research to explore nutrition referral and appointment issues in depth to explore effective strategies that improve nutrition and chronic disease management programs among medically underserved individuals.

\section{CONFlicts of InTEREST Disclosure}

The authors state no conflicts of interest in this study.

\section{REFERENCES}

[1] Walker MH, Murimi MW, Kim Y, et al. Multiple point-of-testing nutrition counseling sessions reduce risk factors for chronic disease among older adults. J Nutr Gerontol Geriatr. 2012; 31(2): 146-157. PMid:22607103. https://doi.org/10.1080/21551197.2012. 678233

[2] Salameh E, Olsen S, Howard D. Nonattendance with clinic followup appointments: Diabetes as exemplar. J Nurse Pract. 2012; 8(10): 797-803. https://doi .org/10.1016/j .nurpra. 2012.09.017

[3] Schectman JM, Schorling JB, Voss JD. Appointment adherence and disparities in outcomes among patients with diabetes. J Gen Intern Med. 2008; 23(10): 1685-1687. PMid:18661189. https: //doi.org/10.1007/s11606-008-0747-1

[4] Johnson BJ, Mold JW, Pontious JM. Reduction and management of no-shows by family medicine residency practice exemplars. Ann Fam Med. 2007; 5(6): 534-539. PMid:18025491. https ://doi .or $\mathrm{g} / 10.1370 / \mathrm{afm} .752$

[5] Sharp DJ, Hamilton W. Non-attendance at general practices and outpatient clinics. BMJ. 2001; 323(7321): 1081-1082. https: //doi.org/10.1136/bmj.323.7321.1081

[6] Hixon AL, Chapman RW, Nuovo J. Failure to keep clinic appointments: implications for residency education and productivity. Fam Med. 1999; 31: 627-630. PMid:10554721.

[7] Krishna M, Amarjothi S. Reminder letters to improve the rate of attendance at community mental health center. Br J Med Pract. 2012; 5(1): 17-20.

[8] Waller J, Hodgkins P. Defaulters in general practice: who are they and what can be done about them? Fam Pract. 2000; 17(3): 252-253 https://doi.org/10.1093/fampra/17.3.252

[9] Clark J. Appointment cancelation options-a new system to help decrease no-show appointments. IACH Informer. 2006.

[10] Pavlovich WD, Waters H, Weller W, et al. Systematic review of literature on the cost-effectiveness of nutrition services. J Am Diet Assoc.
2004; 104(2): 226-232. PMid:14760571. https ://doi .org/10.1 $016 / j \cdot j$ jada. 2003.09 .025

[11] Beck RS, Daughtridge R, Sloane PD. Physician-patient communication in the primary care office: A systematic review. J Am Board Fam Pract. 2002; 15(1): 25-38. PMid:11841136.

[12] Bell CF. Determinants of nutrition appointment nonattendance among male veterans. 2009.

[13] Shook M. Transportation barriers and health access for patient attending a community health center. Field area paper. 2005.

[14] Sarnquist CC, Soni S, Hwang H, et al. Rural HIV-infected women's access to medical care: ongoing needs in California. AIDS Care. 2011; 23(7): 792-796. PMid:21287418. https ://doi .org/10.1 $080 / 09540121.2010 .516345$

[15] Iezzoni LI, Killeen MB, O'day BL. Rural residents with disabilities confront substantial barriers to obtaining primary care. Health Serv Res. 2006.

[16] Guidry JJ, Aday LA, Zhang D, et al. Transportation as a barrier to cancer treatment. Cancer Pract. 1997; 5(6): 361-366. PMid:9397704.

[17] Stubbs ND, Sanders S, Jones DB, et al. Methods to reduce outpatient non-attendance. Am J of Med Sci. 2012; 344(3): 211-219. PMid:22475731. https://doi.org/10.1097/MAJ.0b013e3182 $4997 \mathrm{c} 6$

[18] Perron NJ, Dominice MD, Kossovsky MP, et al. Reduction of missed appointments at an urban primary care clinic: a randomized controlled study. BMC FAM Pract. 2010; 11(1): 79. PMid:20973950. https://doi.org/10.1186/1471-2296-11-79

[19] Delaney NM. Obstacles to attending treatment in an urban mental health clinic: A client's perspective approach to identifying factors influencing treatment attendance. Counselor Education Master's Thesis [Internet]. 2012 - [cited 2018 May 31]. Available from: http: //digitalcommons.brockport.edu/edc_theses/125?utm_ source=digital commons . brockport . edu $\% 2$ Fedc_theses $\% 2$ F125\&utm_medium=PDF\&utm_campaign=PDFCoverPages | 
[20] Alakaam A, Townsend D, Lemacks J. Accuracy of weight status perception related to weight loss stage of change among medically underserved adults. J Epidemiol Res. 2017; 3(1): 37. https : //doi.org/10.5430/jer.v3n1p37

[21] Alakaam A, Lemacks J. Fruit and vegetable consumption, fat intake, and physical activity participation in relation to socio-demographic factors among medically underserved adults. AIMS Public Health. 2015; 2(3): 402-410. PMid:29546116. https ://doi .org/10. 393 4/publichealth.2015.3.402

[22] Geiger SL. Nonattendance rates and barriers to healthcare in outpatient clinic settings. Walden University Scholar Works [Internet]. 2015 - [cited 2018 May 31]. Available from: https ://scholarworks . waldenu . edu/cgi/viewcontent.c gi?article=1221\&context=dissertations

[23] Bell C, Bryant C. Determinants of nutrition appointment attendance among male veterans attending veterans' health administration clinics. J Nutr Educ Behav. 2013; 45(6): 739-744. PMid:23735718. https://doi.org/10.1016/j.jneb.2013.01.013

[24] Martin C, Perfect T, Mantle G. Non-attendance in primary care: The views of patients and practices on its causes, impact and solutions. Fam Pract. 2005; 22(6): 638-643. PMid:16055472. https : //doi.org/10.1093/fampra/cmi076

[25] Bleich SN, Bennett WL, Gudzune KA, et al. National survey of US primary care physicians' perspectives about causes of obesity and solutions to improve care. BMJ Open. 2012; 2(6): e001871. PMid:23257776. https ://doi.org/10.1136/bmjope n-2012-001871

[26] Spikmans FJ, Brug J, Doven MM, et al. Why do diabetic patients not attend appointments with their dietician? J Hum Nutr Diet. 2003; 16(3): 151-158. https://doi.org/10.1046/j.1365-277X.20 $03.00435 . \mathrm{x}$

[27] Probst JC, Laditka SB, Wang J, et al. Effects of residence and race on burden of travel for care: cross sectional analysis of the 2001 US National Household Travel Survey. BMC Health Serv Res. 2007; 11(1): 79. https : //doi .org/10.1186/1472-6963-7-40

[28] Skinner AC, Slifkin RT. Rural/urban differences in barriers to and burden of care for children with special health care needs. J Rural Health. 2007; 23(2): 150-157. PMid:17397371. https://doi.or $\mathrm{g} / 10.1111 / \mathrm{j} .1748-0361.2007 .00082 \cdot \mathrm{x}$

[29] Brown EKA, Shetty V, Delrahim S, et al. Correlates of missed appointments in orofacial injury patients. Oral Surg Oral Med, Oral Pathol Oral Radiol Endodo. 1999; 87(4): 405-410. https: //doi.org/10.1016/S1079-2104(99)70238-6

[30] Begley C, Basu R, Lairson D, et al. Socioeconomic status, health care use, and outcomes: Persistence of disparities over time. Epilepsia. 2011; 52(5): 957-964. PMid:21320113. https://doi.org/10.1 $111 / \mathrm{j} .1528-1167.2010 .02968 . \mathrm{x}$

[31] Neal RD, Heywood PL, Morley S. Real world data-retrieval and validation of consultation data from four general practices. Fam Pract. 1996; 13(5): 455-461. https://doi.org/10.1093/fampra/13. 5.455 